\title{
Normal Urine Test Result
}

National Cancer Institute

\section{Source}

National Cancer Institute. Normal Urine Test Result. NCI Thesaurus. Code C35866.

A laboratory test result indicating that the analysis of a urine sample revealed normal values. 